\title{
Clinical profile and obstetric outcome in pregnancies complicated by heart disease: a five year Indian rural experience
}

\author{
Nilajkumar D. Bagde*, Madhuri N. Bagde, Poonam Varma Shivkumar, Surekha Tayade
}

Department of Obstetrics \& Gynecology, MGIMS, Sewagram, India

Received: 31 December 2012

Accepted: 6 January 2013

*Correspondence:

Dr. Nilajkumar D. Bagde

E-mail: mailnilaj@gmail.com

\begin{abstract}
Background: Cardiac diseases are a major cause of morbidity and mortality in pregnant women in the developing world. This study illustrates the problem in rural India focusing on patterns of diseases, clinical features, and pregnancy outcome in these women.

Methods: A retrospective analysis of five year data, from 2006 to 2010 for all patients admitted with cardiac disease in pregnancy.

Results: Past history of heart disease was present in $70 \%$. Rheumatic heart disease was predominant type in $83 \%$ and the chief complaint at admission was breathlessness in $44 \%$. Mitral stenosis was the commonest lesion in $55 \%$ and mitral regurgitation with or without stenosis in $48 \%$. Preeclampsia was seen in $20 \%$ and preterm labor in $10 \%$. Spontaneous vaginal delivery was seen in $41 \%$ and cesarean in $20.6 \%$.

Conclusions: Heart disease in pregnancy is a high risk condition has a major impact on pregnancy. Associated obstetric complications along with lack of knowledge and ignorance regarding the pathology lead to unpleasant obstetric outcomes.
\end{abstract}

Keywords: Cardiac, Complications, Pregnancy

\section{INTRODUCTION}

Cardiac diseases complicate $1 \%$ of pregnancies the commonest being rheumatic heart disease. ${ }^{1}$ Diagnosis of heart disease during pregnancy is a challenge as common clinical features of cardiac lesions like breathlessness, pedal edema, and murmurs mimic normal pregnancy. Cardiac output increases by $30-50 \%$ during pregnancy and a further increase during labor and delivery imposes a burden on the diseased heart leading to complications and death.

Cardiac disorders contribute to approximately $20.5 \%$ of maternal deaths. ${ }^{2}$ With the advent of modern therapeutic options, more and more women with cardiac disease are reaching the reproductive age. Moreover these patients are now attempting pregnancy multiple times due to availability of life saving modern therapy. Obstetric complications like preeclampsia, anemia, preterm labor, and fetal growth restriction are not uncommon in patients with heart disease. Ignorance about pregnancy related complications compounding heart disease is exaggerated in the rural setup.

Ours is a tertiary referral center for a large rural population. One third patients visiting this hospital come from rural areas. Lack of knowledge about health care, traditional customs and beliefs, as well as gender related disparity create barriers leading to underutilization of available health care resources. Additionally, the social norm of higher gravidity and parity combined with lack of awareness about contraception lead to repeated conceptions. People rely heavily on local doctors and quacks that may be deficient in the necessary skills to diagnose heart disease. Another social issue for implementing screening programs is acceptance on part of the people. If a young female is labeled as having heart disease, problems related to marriage and issues related to childbearing arise which may be unacceptable according to the social norms. All these factors combine and lead to dismal obstetric outcomes. 
The aim of the current study is to analyze the patterns of heart disease complicating pregnancy, to study any associated obstetric or medical complications and their impact on pregnancy and heart disease, and to study the pregnancy outcome in these patients in a rural tertiary care center.

\section{METHODS}

Medical discharge cards of all patients with a diagnosis of heart disease at the time of discharge or death in the Obstetrics and Gynecology Department during a five year period from 2006 to 2010 were recovered using the computerized Hospital Information System (HIS) of the Hospital after approval by the institutional ethical committee. The HIS is a comprehensive collection of all the data regarding any patient visiting our institute. Patients are provided with Computerized Registration (CR) numbers. The numbers are scanned every time the patient visits the hospital. Electronic version of the discharge cards prepared by senior residents and corrected by consultants, are kept as a part of the patient medical record. This includes a brief history at admission, clinical examination, diagnosis, all investigations performed and treatment provided as well as future treatment plan. Patients are classified into various disease categories based on discharge card summaries using different ICD codes and compartmentalized according to the departments where they were admitted.

There were 29 patients with pregnancy complicated by heart disease. Discharge cards of these patients were studied in details and their investigations reviewed. For patients admitted more than once, all discharge cards were studied and details noted. Effort was made to extract all possible information and the actual admission papers were examined to retrieve missing data. If despite this, data was unavailable it was included in the study as "not available'.

Data was extracted by a single trained data extractor and cross checked by an independent observer for errors. Intention to treat analysis was performed using STATA version10.

\section{RESULTS}

\section{Demographic characteristics}

The mean age of the patients was $24.51 \pm 4.42$ years. Most of the patients (44\%) were primigravida at admission, $24 \%$ pregnant for the second time, $27 \%$ gravida three or higher and $3 \%$ admitted postpartum. Approximately $51 \%$ were nullipara, $27 \%$ para one, $17 \%$ para two, and $3.5 \%$ para three. $13 \%$ had one living child, $3.5 \%$ had 2 and $3.5 \%$ had 4 living children at the time of admission. The average admissions for a single patient was $1.37 \pm 0.56$, of these $65 \%$ were admitted once, $31 \%$ twice, and $3.5 \%$ admitted three times at the hospital during their antenatal period.

The mean gestational age at the time of first admission was $26.69 \pm 13.25$ weeks and ranged between 5 to 42 weeks (Table 1). There were 9 patients $(31 \%)$ with gestational age $\geq 37$ weeks (reached full term) at the time of first admission, one (3.5\%) was admitted postpartum with puerperal sepsis and data was missing for two patients $(7 \%)$. The gestational age at the time of delivery was between $37-42$ weeks (full term) in $41 \%$ cases and $<37$ weeks in $10 \%$ cases. Two patients $(7 \%)$ died undelivered at the gestational age of 27 and 28 weeks respectively.

Table 1: Age distribution, gestational age at admission and delivery for all patients, gestational age at delivery for term and preterm patients with heart disease complicating pregnancy.

\begin{tabular}{|c|c|c|c|c|c|}
\hline & Mean & Minimum & Maximum & Proportion & $95 \% \mathrm{CI}$ \\
\hline Age $(n=29)$ & $24.57 \pm 4.42$ & 16 & 33 & - & - \\
\hline $\begin{array}{l}\text { Gestational age at admission } \\
\text { in weeks for all patients } \\
\left(n=26^{*}\right)\end{array}$ & $26.7 \pm 13.25$ & 5 & 42 & 89 & 0.77 to 1.01 \\
\hline $\begin{array}{l}\text { Gestational age at delivery in } \\
\text { weeks }\left(n=15^{\$}\right)\end{array}$ & $37.86 \pm 2.38$ & 33 & 42 & 51 & 0.32 to 0.71 \\
\hline $\begin{array}{l}\text { Gestational age at delivery } \geq \\
37 \text { weeks }(n=12)\end{array}$ & $39.25 \pm 1.66$ & 37 & 42 & 41 & 0.22 to 0.60 \\
\hline $\begin{array}{l}\text { Gestational age at delivery }> \\
20 \text { to }<37 \text { weeks }(n=3)\end{array}$ & $34.33 \pm 1.15$ & 33 & 35 & 10 & -0.01 to 0.22 \\
\hline
\end{tabular}




\section{Clinical profile}

Prior history of heart disease was present in $70 \%$ patients. After admission, rheumatic heart disease was observed in $83 \%, 10 \%$ had congenital heart disease and $3.5 \%$ had postpartum cardiomyopathy or hypertrophic obstructive cardiomyopathy. Mitral stenosis was the predominant valvular lesion in $55 \%$ followed by mitral regurgitation occurring either alone or in combination with mitral stenosis in $48 \%$.

Breathlessness was the chief complaint at admission in $44 \%$, labor pains in $13 \%$, and bleeding per vaginum or backache in $6 \%$. History of surgery for correction of cardiac defect was present in two $(6 \%)$ patients and both had some residual lesion at the time of admission (Table 2).

Table 2: Chief complaints and types of lesions in women with cardiac disease complicating pregnancy.

\begin{tabular}{|ll|}
\hline \multicolumn{2}{|l|}{ Chief complaint } \\
\hline Amenorrhea & 10 \\
\hline Breathlessness & 44 \\
\hline Labor pains & 13 \\
\hline Bleeding Per vaginum & 7 \\
\hline Wants MTP & 7 \\
\hline Edema feet & 3 \\
\hline Cough & 3 \\
\hline Backache & 3 \\
\hline History of heart disease & \\
\hline Yes & 70 \\
\hline No & 20 \\
\hline Not available & 10 \\
\hline Type of heart disease & \\
\hline Rheumatic & 82 \\
\hline Congenital & 10 \\
\hline Peripartum Cardiomyopathy & 3 \\
\hline $\begin{array}{l}\text { Hypertrophic obstructive } \\
\text { cardiomyopathy }\end{array}$ & 3 \\
\hline Valvular lesion & 7 \\
\hline Mitral stenosis & 55 \\
\hline Mitral regurgitation & 48 \\
\hline Aortic regurgitation & 7 \\
\hline Aortic stenosis & \\
\hline Surgery for cardiac disease & \\
\hline MTP: Medical termination of pregnancy \\
\hline
\end{tabular}

\section{Obstetric or medical complications and pregnancy outcome}

Associated obstetric complications included preeclampsia in $20 \%$, preterm delivery in $10 \%$, severe anemia and gestational diabetes in $3.5 \%$ each. Medical disorders that complicated heart disease were sickle cell trait in $7 \%$ and hyperthyroidism in $3.5 \%$. The patient that had hyperthyroidism also had preeclampsia. Pulmonary edema occurred in $7.5 \%$ patients and all of them died.
There were two patients $(7.5 \%)$ that were diagnosed as bronchial asthma were treated as cases of bronchial asthma in the past at private hospitals before being diagnosed as heart disease. Congestive cardiac failure developed in $9(31 \%)$ patients at some point of time during the current pregnancy of which 4 (44\%) died.

Spontaneous vaginal delivery occurred in $41 \%$, cesarean section in $20.6 \%$, and $7 \%$ died in the antenatal period. Pregnancy was terminated by either elective or spontaneous abortion in 8 out of 9 patients admitted for the first time before 20 weeks of gestation. Of these, $33 \%$ had presented with breathlessness at admission and $44 \%$ had presented for medical termination of pregnancy or with incomplete abortion. One patient was referred as a case of vesicular mole as she developed cardiac failure after evacuation at a private hospital. Data regarding pregnancy outcome was unavailable in one $(3.5 \%)$ patient (Table 3).

Table 3: Associated obstetric or medical condition and pregnancy outcome in women with cardiac disease complicating pregnancy.

\begin{tabular}{|ll|}
\hline Obstetric or medical complication & Proportion \\
\hline Preeclampsia & \\
\hline Preterm delivery & 20 \\
\hline IUGR & 10 \\
\hline Post date & 7 \\
\hline Severe anemia & 3.5 \\
\hline Sickle cell trait & 3.5 \\
\hline Gestational diabetes & 7 \\
\hline Hyperthyroidism & 3.5 \\
\hline Obstetric outcome & 3.5 \\
\hline Died in the antenatal period & \\
\hline Cesarean section & 7 \\
\hline Induced abortion & 20.6 \\
\hline Spontaneous abortion & 17 \\
\hline Vaginal delivery & 10 \\
\hline
\end{tabular}

IUGR: Intrauterine growth restriction

\section{DISCUSSION}

In this study, most of the patients were young and gravida two or higher. Past history of heart disease was present in $70 \%$ patients $(50 \%$ primigravidas and $86 \%$ gravida two or higher) and $20 \%$ had one or more living children on admission to the hospital. This means that patients were attempting pregnancy despite knowing that they had a problematic heart. The reason for such behavior might be the social norm of high parity or lack of contraceptive knowledge. Another reason could be ignorance on the part of the females as well as the family and society about the severity of the situation and the possible consequences of repeated pregnancies.

The ratio of rheumatic to congenital heart disease was 8.3:1. This is due to high prevalence of rheumatic heart 
disease in India ${ }^{3}$ especially in females as females remain confined to the households and there is lack of healthcare access. ${ }^{4}$ A similar ratio of 7.62:1 has been reported by Bhatla et al. ${ }^{5}$ Another Indian study found the ratio of RHD to CHD as 3.2:1. ${ }^{6}$ The difference can be explained as the above study was carried out in an urban tertiary care centre in one of the most developed cities of India. In the industrialized nations, the ratio of RHD to CHD is low due to decreased prevalence of rheumatic fever as well as early diagnosis and management of congenital lesions. ${ }^{7,8}$

A study in China observed 1142 women with heart disease that delivered over a 15 year period and found that peripartum cardiomyopathy constituted $2.03 \%$ of all pregnancies with heart disease. ${ }^{9}$ We found an interesting case of vesicular mole associated with peripartum cardiomyopathy. Another report of vesicular mole and familial peripartum cardiomyopathy has been described ${ }^{10}$ where a 16 year old primigravida with family history of peripartum cardiomyopathy underwent suction evacuation for vesicular mole. She developed congestive cardiac failure after 3 months and cardiac biopsy showed fibrosis and hypertrophy. The association of molar pregnancy with cardiomyopathy has been proposed to be inherited through paternally impregnated genes. ${ }^{11}$

Irrespective of the type of underlying cardiac disease, mitral stenosis was the commonest valvular lesion in accordance with other authors. ${ }^{5,12,13}$ Mitral valve affection has the potential of leading to most ominous consequences. ${ }^{14}$ Fixed cardiac output due to the stenosed valve precludes hemodynamic cardiac compensations during pregnancy. Cardiac failure may develop in asymptomatic patients with mild to moderate disease during antenatal or peripartum phase and chances of atrial fibrillation are high. ${ }^{15}$ Mitral regurgitation was the second commonest lesion similar to other studies. ${ }^{3,16}$ It is well tolerated during pregnancy and mild regurgitation poses a low risk of complications. ${ }^{17}$ A recent Brazilian study however reported that cardiac adaptations in women with mitral regurgitation are dissimilar from normal women and optimal cardiac remodeling does not occur in these patients. $^{18}$

Most women presented with history of breathlessness. Akther et al also reports shortness of breath as the chief complaint in $60 \%$ patients with congenital heart disease complicating pregnancy. ${ }^{19} 61.5 \%$ patients presented with this complaint in the third trimester when cardiac demand reaches its peak. Pulmonary congestion is the commonest cause of breathlessness and hence it is important to recognize this symptom early and advocate extra vigilance while managing these patients. Out of the six maternal deaths, four presented with breathlessness as the chief complaint and all developed congestive cardiac failure.

Patients with heart disease are not immune to obstetric complications. Conditions like preeclampsia enforce an added burden on an already compromised system.
Unfortunately reports about such affection are few. A prospective study in Bangladesh ${ }^{19}$ reported a $4 \%$ rate of preeclampsia and $2 \%$ eclampsia in women with congenital heart disease, while a retrospective study in Netherlands reported preeclampsia in $12.2 \% .^{20}$ Another case report of anesthetic challenges in a patient with severe aortic and mitral stenosis along with pulmonary edema and toxemia of pregnancy requiring cesarean section recommended the principles of maintaining proper airway, hemodynamic stability, maintain intravascular volume and measures to prevent convulsions. ${ }^{21}$ Preterm delivery complicated $10 \%$ of our patients. Preterm labor was observed in $10 \%$ pregnancies with cardiac disease according to a study in north India ${ }^{12}$ and another Indian study reported $27.7 \%$ preterm births. ${ }^{6}$ The difference may be accounted by the fact that most of the females in our study that presented before 20 weeks of gestation either opted for medical termination of pregnancy or aborted spontaneously (Table 3).

Amongst associated medical illnesses, sickle cell trait was the most frequent. The sickle mutation is endemic amongst certain communities in central India and MGIMS Sewagram has a huge inflow of patients coming from these communities. Sickle cell leads to anemia and high cardiac output state. A study demonstrated that echocardiographic studies performed in patients with sickle cell disease and compared with normal pregnant patients revealed a higher stroke volume and cardiac output, systolic function was comparable to the normal group but diastolic function was decreased in sickle cell group indicating a lower ventricular compliance. ${ }^{22}$ We do not know if the same holds true for sickle cell trait. Hyperthyroidism and preeclampsia both have the potential to precipitate cardiac failure. There was one patient that had hyperthyroidism and preeclampsia complicating rheumatic heart disease. She did not have a history of cardiac disease and was admitted at the gestational age of 27 weeks with hyperthyroidism and preeclampsia in congestive cardiac failure. There was associated lower respiratory tract infection and she succumbed to her condition.

Pulmonary edema developed in $7.5 \%$ patients and none of them survived. Akhter et al reported pulmonary edema in $8.35 \%$ patients with valvular heart disease in a prospective multicenter study at Bangaldesh. ${ }^{23}$ In an African study, pulmonary edema was present at admission in 36 out of 50 patients and there were 17 maternal deaths. ${ }^{16}$

Cesarean section was performed for obstetric indication in $20.6 \%$ patients. In contrast, a similar study in South Africa reported $16.66 \%$ elective cesarean sections for severe heart disease. ${ }^{13}$ The JCS joint working group recommends that assisted vaginal delivery is preferred and cardiac indications for cesarean section include cardiac dysfunction, patient at risk of hemodynamic instability, pulmonary hypertension, uncontrolled arrhythmia, mechanical valve prosthesis, and patients with cyanosis. ${ }^{24}$ At our centre, most of the patients that 
presented before 20 weeks of pregnancy opted for termination of pregnancy. We do not have details about the reason for such behavior.

\section{CONCLUSIONS}

Cardiac disease in pregnancy is an important entity and needs to be given utmost priority. Our study is limited by its retrospective nature. Some of the data was missing and may have affected our results.

This study throws insight into the prevailing conditions in rural India. We expect more severe outcomes in the actual community as home deliveries by untrained birth attendants and unattended deliveries are common. Rheumatic heart disease continues to be the leading cause of cardiac illness and is associated with unpleasant outcomes. In the second trimester cardiac demands begin to approach their zenith. This is a crucial period and chances of cardiac failure are escalated. It is important to educate masses about these concepts and implement screening camps to detect young women with cardiac defects.

The need for providing doorstep services to people in rural India and training rural health workers to motivate every pregnant woman to seek expert care during her pregnancy cannot be overemphasized and must be undertaken with utmost priority.

Funding: No funding sources

Competing interests: There are no competing interests to declare

Ethical approval: The study was approved by the institutional ethical committee

\section{REFERENCES}

1. Cunningham FG, Leveno KJ, Bloom SL, Hauth JC, Rouse DJ, Spong CY, editors. Williams Obstetrics. 23rd ed. Cardiovascular Disease. United States of America: McGraw-Hill Companies; 2010.

2. Burlingame J, Horiuchi B, Ohana P, Onaka A, Sauvage LM. The contribution of heart disease to pregnancy-related mortality according to the pregnancy mortality surveillance system. J Perinatol 2012;32:163-9.

3. Grover A, Dhawan A, Iyengar SD, Anand IS, Wahi PL, Ganguly NK. Epidemiology of rheumatic fever and rheumatic heart disease in a rural community in northern India. Bull World Health Organ 1993;71:59-66.

4. Padmavati S. Rheumatic heart disease: prevalence and preventive measures in the Indian subcontinent. Heart 2001;86:127.

5. Bhatla N, Lal S, Behera G, Kriplani A, Mittal S, Agarwal N, et al. Cardiac disease in pregnancy. Int $\mathbf{J}$ Gynaecol Obstet 2003;82:153-9.
6. Doshi HU, Oza HV, Tekani H, Modi K. Cardiac disease in pregnancy--maternal and perinatal outcome. J Indian Med Assoc 2010;5:108:278-80.

7. Van Mook WN, Peeters L. Severe cardiac disease in pregnancy, part II: impact of congenital and acquired cardiac diseases during pregnancy. Curr Opin Crit Care 2005;10:435-48.

8. Thorne SA. Pregnancy in heart disease. Heart 2004;3:450-6.

9. Liu H, Xu JW, Zhao XD, Ye TY, Lin JH, Lin QD. Pregnancy outcomes in women with heart disease. Chin Med J (Engl) 2010;123:2324-30.

10. Massad LS, Reiss CK, Mutch DG, Haskel EJ. Familial peripartum cardiomyopathy after molar pregnancy. Obstet Gynecol 1993;5:886-8.

11. Billieux $\mathrm{MH}$, Petignat $\mathrm{P}$, Fior $\mathrm{A}$, Mhawech $\mathrm{P}$, Blouin JL, Dahoun S, et al. Pre-eclampsia and peripartum cardiomyopathy in molar pregnancy: clinical implication for maternally imprinted genes. Ultrasound Obstet Gynecol 2004;23:398-401.

12. Sawhney H, Aggarwal N, Suri V, Vasishta K, Sharma Y, Grover A. Maternal and perinatal outcome in rheumatic heart disease. Int $\mathbf{J}$ Gynaecol Obstet 2003;80;9-14.

13. Nqayana T, Moodley J, Naidoo DP. Cardiac disease in pregnancy. Cardiovasc J Afr 2008;19:145-51.

14. Essop MR, Nkomo VT. Rheumatic and nonrheumatic valvular heart disease: epidemiology, management, and prevention in Africa. Circulation 2005;112:3584-91.

15. Siu S, Colman JM. Cardiovascular problems and pregnancy: an approach to management. Cleve Clin J Med 2004;71:977-85.

16. Diao M, Kane A, Ndiaye MB, Mbaye A, Bodian M, Dia MM, et al. Pregnancy in women with heart disease in sub-Saharan Africa. Arch Cardiovasc Dis 2011;104:370-4.

17. Regitz-Zagrosek V, Seeland U, Geibel-Zehender A, Gohlke-Bärwolf C, Kruck I, Schaefer C. Cardiovascular diseases in pregnancy. Dtsch Arztebl Int 2011;108:267-73.

18. Borges VT, Matsubara BB, Magalhães CG, Peraçoli JC, Rudge MV. Effect of physiological overload on pregnancy in women with mitral regurgitation. Clinics (Sao Paulo) 2011;66:47-50.

19. Akhter N, Rahman F, Salman M, Anam K, Banerjee SK, Amin SA, et al. Outcome of pregnancy in patients with congenital heart diseases. Mymensingh Med J 2011;20:620-4.

20. Drenthen W, Boersma E, Balci A, Moons P, RoosHesselink JW, Mulder BJ et al. Predictors of pregnancy complications in women with congenital heart disease. Eur Heart J 2010;31:2124-32.

21. Dua S, Maurtua MA, Cywinski JB, Deogaonkar A, Waters JH, Dolak JA. Anesthetic management for emergency cesarean section in a patient with severe valvular disease and preeclampsia. Int $\mathbf{J}$ Obstet Anesth 2006;15:250-3. 
22. Veille JC, Hanson R. Left ventricular systolic and diastolic function in pregnant patients with sickle cell disease. Am J Obstet Gynecol 1994;170:107-10.

23. Akhter N, Rahman F, Salman M, Anam K, Begum $\mathrm{N}$, Naher $\mathrm{S}$, et al. Valvular heart disease in pregnancy: maternal and fetal outcome. Mymensingh Med J 2011;20:436-40.

24. JCS Joint Working Group. Guidelines for indication and management of pregnancy and delivery in women with heart disease (JCS 2010): digest version. Circ J 2012;76:240-60.

25. Sartain JB, Anderson NL, Barry JJ, Boyd PT, Howat PW. Rheumatic Heart Disease in Pregnancy - cardiac and obstetric outcomes. Intern Med J 2012. doi: 10.1111/j.1445-5994.2012.02725.x

DOI: $10.5455 / 2320-1770$. ijrcog20130209

Cite this article as: Bagde ND, Bagde $\mathrm{MN}$, Shivkumar PV, Tayade S. Clinical profile and obstetric outcome in pregnancies complicated by heart disease: a five year Indian rural experience. Int J Reprod Contracept Obstet Gynecol 2013;2:52- 